\title{
BMJ Open Cohort profile: Understanding Pregnancy Signals and Infant Development (UPSIDE): a pregnancy cohort study on prenatal exposure mechanisms for child health
}

Thomas O'Connor, ${ }^{1,2,3,4,5}$ Meghan Best, ${ }^{2}$ Jessica Brunner, ${ }^{1,2,6}$ Allison Avrich Ciesla, ${ }^{1}$ Allison Cunning, ${ }^{2}$ Ntemena Kapula, ${ }^{2,6}$ Amber Kautz, ${ }^{7}$ Leena Khoury, ${ }^{1,2}$ Allison Macomber, ${ }^{2}$ Ying Meng, ${ }^{6}$ Richard K Miller, ${ }^{2}$ Hannah Murphy, ${ }^{2}$ Carolyn M Salafia, ${ }^{8,9}$ Ana Vallejo Sefair, ${ }^{5}$ Jishyra Serrano, ${ }^{2}$ Emily Barrett (i) ,2,10,11 UPSIDE study

To cite: O'Connor T, Best $\mathrm{M}$, Brunner J, et al. Cohort profile: Understanding Pregnancy Signals and Infant Development (UPSIDE): a pregnancy cohort study on prenatal exposure mechanisms for child health. BMJ Open 2021;11:e044798. doi:10.1136/ bmjopen-2020-044798

- Prepublication history for this paper is available online. To view these files, please visit the journal online (http://dx.doi. org/10.1136/bmjopen-2020044798).

Received 14 September 2020 Revised 08 February 2021 Accepted 04 March 2021
Check for updates

(C) Author(s) (or their employer(s)) 2021. Re-use permitted under CC BY-NC. No commercial re-use. See rights and permissions. Published by BMJ.

For numbered affiliations see end of article.

Correspondence to

Dr Emily Barrett;

emily.barrett@eohsi.rutgers.edu

\section{ABSTRACT}

Purpose Extensive research suggests that maternal prenatal distress is reliably related to perinatal and child health outcomes-which may persist into adulthood. However, basic questions remain regarding mechanisms involved. To better understand these mechanisms, we developed the Understanding Pregnancy Signals and Infant Development (UPSIDE) cohort study, which has several distinguishing features, including repeated assessments across trimesters, analysis of multiple biological pathways of interest, and incorporation of placental structure and function as mediators of child health outcomes.

Participants Women with normal risk pregnancies were recruited at $<14$ weeks gestation. Study visits occurred in each trimester and included extensive psychological, sociodemographic, health behaviour and biospecimen collection. Placenta and cord blood were collected at birth. Child visits (ongoing) occur at birth and 1, 6, 12, 24, 36 and 48 months of age and use standard anthropometric, clinical, behavioural, biological and neuroimaging methods to assess child physical and neurodevelopment.

Findings to date We recruited 326 pregnancies; 294 $(90 \%)$ were retained through birth. Success rates for prenatal biospecimen collection were high across all trimesters (96\%-99\% for blood, 94\%-97\% for urine, $96 \%-99 \%$ for saliva, $96 \%$ of placentas, $88 \%$ for cord blood and $93 \%$ for buccal swab). Ninety-four per cent of eligible babies $(n=277)$ participated in a birth examination; postnatal visits are ongoing.

Future plans The current phase of the study follows children through age 4 to examine child neurodevelopment and physical development. In addition, the cohort participates in the National Institutes of Health's Environmental influences on Child Health Outcomes programme, a national study of 50000 families examining early environmental influences on perinatal outcomes, neurodevelopment, obesity and airway disease. Future research will leverage the rich repository of biological samples and clinical data to expand research on the mechanisms of child health outcomes in relation to
Strengths and limitations of this study

- The Understanding Pregnancy Signals and Infant Development cohort features intensive, serial biospecimen and questionnaire collection from the first trimester of pregnancy through age 4 years that will allow us to test hypotheses regarding the pathways by which maternal distress impacts children's physical and neurodevelopment during critical and sensitive periods.

- Our comprehensive assessment of the placenta, including both morphometric and molecular markers, provides novel data on the role that this understudied organ plays as a mediator of the association between maternal exposures and child outcomes.

- The study is not designed to assess clinical phenotypes in pregnant women (eg, pre-eclampsia) and children (eg, autism).

environmental chemical exposures, genetics and the microbiome.

\section{INTRODUCTION}

For several decades, epidemiological studies have provided robust evidence of an association between maternal prenatal distress and child health outcomes. ${ }^{1-6}$ The large and growing collection of studies that has emerged from both high-income and low/ middle-income countries, suggests that prenatal maternal distress is a plausible illustration of a 'developmental programming effect' on child health outcomes. ${ }^{7-12}$ The developmental programming model proposes that in utero exposures instigate an adaptive response in the foetus/child that is carried forward in development and has 
persisting effects on behaviour and biology. ${ }^{13-18}$ Central to this hypothesis is the concept that early exposures have a privileged-or different—effect on biological systems than those occurring later in development. ${ }^{19}$ In other words, when exposures occur very early in development, physiology may change (either adaptively or pathologically) resulting in long-lasting or permanent impacts on health and well-being. A classic example of this is the 'thrifty phenotype' whereby nutrient deprivation during prenatal development may lead to reduced fetal growth and metabolic changes to conserve energy. ${ }^{20}$ In the presence of subsequent nutrient surplus (characteristic of the modern western diet), this metabolic conservation may lead to obesity and metabolic disease. ${ }^{21}$ The resulting clinical and public health implications of this model are substantial because they suggest that the timing of intervention may be as important as its content. The aim of this paper is to introduce a new cohort, Understanding Pregnancy Signals and Infant Development (UPSIDE), which includes several measurement and design advantages to advance our understanding of maternal prenatal psychosocial distress and child health outcomes.

A key exposure variable in this large collection of studies may be broadly interpreted as prenatal maternal psychological distress. Assessment of maternal psychological distress can derive from many sources, including clinical interviews as well as maternal self-report inventories of anxiety, depressive symptoms, trauma, major life-event stressors and 'pregnancy-specific' worry. The persistence of reported impacts of maternal psychological distress on child outcomes, despite variation in exposure measurement, suggests that the association is robust. ${ }^{22-27} \mathrm{We}$ adopt the term 'distress' when referring in general to this research and identify specific measures in the research protocol that index this broader construct. The corollary-how maternal experience of or exposure to distress creates an exposure variable for the foetus-is far less clear and likely involves multiple, interdependent biological pathways. That is, if distress is indeed a causal factor, it may operate via neuroendocrine, immune, autonomic or other physiological mechanisms. ${ }^{28-31}$ Initial research on the mediating mechanisms, based on strong evidence from experimental animal studies, targeted the hypothalamic-pituitary-adrenal (HPA) axis. ${ }^{32}$ The biological case for its involvement in the stress response (most typically in the form of cortisol, the downstream product of HPA activation) is certain, its transplacental transfer is wellestablished, and the application to placental mechanisms is evident (placental enzyme 11- $\beta$-HSD2) ${ }^{33}{ }^{34}$ Nonetheless, that biological model is too limited. Human studies have not provided consistent evidence that prenatal maternal distress impacts child development through HPA-related mechanisms. ${ }^{32}{ }^{35-39}$ Moreover, several lines of research raise alternative mechanisms. One of the most important of these is maternal inflammation, represented by research on the maternal immune activation model. Research findings show that circulating proinflammatory markers in pregnancy predict an increased risk of significant neurodevelopmental problems in the child. ${ }^{40-45}$ Other studies indicate that prenatal sex steroids may also be a plausible predictor of child development $^{46}$ and may be confounded with stress physiology. ${ }^{47-50}$ Although many current and past pregnancy cohort studies have examined the relationship between maternal psychosocial measures and child outcomes, few have gone beyond the HPA axis to examine additional biological pathways. Accordingly, a first major methodological and conceptual strength of the UPSIDE study is the assessment of biomarkers relevant to alternative pathways (eg, cytokine profiles, steroidogenic activity) across pregnancy and in multiple biological sample types (eg, maternal blood, cord blood, placenta).

A second key feature of the UPSIDE study is its focus on and intensive assessment of the maternal-fetal-placenta unit. Despite the placenta's critical role in transmitting maternal signals to the developing foetus, direct measurement of the placenta has been notably absent from the vast majority of studies on prenatal distress and child development. ${ }^{51}{ }^{52}$ There are both practical and scientific reasons for the limited research that integrates interrogation of the placenta in studies of prenatal exposures and child outcomes. The practical matter concerns sample collection and processing, particularly the 24/7 coverage that this requires if spontaneous deliveries are included. Scientifically, there is variability among studies in which placental markers are assessed; placenta weight, gene expression and epigenetics have all received some attention, almost always in separate reports. In this cohort study, we expand direct, comprehensive measurement of the placenta to advance the field in several important ways. First, it is increasingly clear that the placenta contributes to maternal perinatal health, ${ }^{53-55}$ with clear implications for neonatal and, by extension, child health. It is also becoming more widely appreciated that prenatal exposures (including maternal distress but also environmental exposures) may alter placenta structure and function. ${ }^{56-58}$ Finally, there is now a growing evidence base linking placenta measures to child outcomes such as obesity and neurodevelopment. ${ }^{59-61}$ What has been missing from this field are prospective pregnancy cohort studies that track mother-child dyads from early gestation through early childhood and incorporate placenta mechanisms. To that end, the UPSIDE study includes extensive measurement of placenta structure and function from imaging, histology, and immunohistochemistry, genetics, and pathology reports.

In addition to these conceptual advances, UPSIDE includes several key design elements that will inform our study of the multiple physiological pathways by which maternal psychological stress may impact child development. These include: (1) serial maternal questionnaire and biomarker data across all trimesters to examine critical and sensitive windows of gestation; (2) paediatric visits at seven time points from birth to 4 years of age to assess neurodevelopment as well as growth, reproductive development, and HPA axis activity; (3) consideration of 
potentially important covariates and confounders that are sometimes overlooked in studies of child development (eg, maternal and child diet, physical activity, sleep).

\section{Primary aims}

UPSIDE is funded through several major research grants that have informed the design of the study and included activities. The funding stream that started the cohort (R01HD083369) had the over-arching goal of testing the hypothesis that prenatal maternal anxiety programmes sex steroid pathways leading to changes in placental structure and function, and ultimately sex differences in physical, neurocognitive and social behaviours in infancy through 12 months of age. Soon after, additional study activities were funded through the National Institutes of Health's (NIH's) Environmental influences on Child Health Outcomes (ECHO) programme the largest American study of early childhood health and development ever undertaken, with up to 50000 participating mother-child dyads from cohort studies around the USA (UG3/UH3OD023349). The ECHO funding allowed us to expand the contributions of the cohort to consider inflammatory mechanisms, extend child follow-up to age 4 , and add a more intensive battery of outcome measures. Additionally, as part of ECHO, data and biospecimens from UPSIDE are harmonised with those of the other participating cohorts in order to address ECHO-wide scientific priorities. ${ }^{62}$ With multiple biological pathways of interest now considered in UPSIDE, we are well poised to test competing hypotheses about the biological mechanisms by which maternal distress impacts children's development. The broad aims that guide research in this cohort are described below.

- Identify evidence of prenatal maternal distress-related alterations in HPA, inflammatory and sex steroid hormone pathways in the placenta and cord blood.

- Examine prenatal distress and sex steroid activity (in mother, placenta and cord blood) in relation to sexdependent physical and neurodevelopment.

- Examine prenatal distress and inflammatory markers (in mother, placenta, cord blood and infant) in relation to measures of neurodevelopment (neurocognitive and behavioural measurements, brain imaging and electroencephalogram (EEG)) and child physical development and adiposity (birth to age 4 ).

\section{COHORT DESCRIPTION}

\section{Study setting and recruitment}

From December 2015 to April 2019, women were recruited during their first trimester of pregnancy from outpatient obstetric clinics affiliated with the University of Rochester. Eligibility criteria included: $<14$ weeks gestation, age 18 or older, singleton pregnancy, no known substance abuse problems or a history of psychotic illness, and ability to communicate in English. Women with major endocrine disorders (such as polycystic ovary syndrome), high-risk pregnancies or significant obstetric problems were excluded. Infants born prior to 37 weeks gestation were not included in postnatal study phases. No screening for distress was conducted prior to consent; instead we recruited from clinics who serve women at high psychosocial risk. Women who were recruited and delivered and then had a subsequent pregnancy during this time period were also invited to participate for the second pregnancy, towards the goal of examining intraindividual differences in prenatal maternal and placental biology as a future research direction.

\section{Patient and public involvement \\ No patient involvement.}

\section{Overview of UPSIDE study activities}

Prenatal participation in UPSIDE consisted of face-to-face visits in each trimester, including biospecimen collection and questionnaires. At birth, the placenta and cord blood were collected, and the infant underwent a neonatal physical examination prior to hospital discharge. Additional postnatal visits (ongoing) occur when children are 1, 6, $12,24,36$ and 48 months of age and include biospecimen collection as well as observational and performance-based assessments of the child; parents complete questionnaires on child and family health and exposures. Child outcome timepoints were chosen based on consideration of several key criteria: (1) developmental milestones and critical windows; (2) coincidence with routine well-child appointments; (3) spacing of visits to allow for repeated measures within domains over time, while minimising participant burden and loss to follow-up and (4) constraints of funding timelines. In general, data collection for UPSIDE follows several key principles: (1) repeated measures over time; (2) complementary biospecimen and questionnaire data collection; (3) ability to test multiple/competing hypotheses. Biospecimen collection and study activities are summarised in tables 1 and 2, respectively, and described in greater detail.

\section{Maternal survey measures}

At baseline, participants provided sociodemographic information; time-sensitive data (eg, employment, marital status) were updated at each study visit. Additional measures relevant to psychological distress, psychosocial risk and the biological pathways of interest were collected during pregnancy as described below. To assess possible timing effects of exposures as well as changes in maternal distress across pregnancy, assessments were repeated in each trimester and, when applicable, at postnatal visits.

\section{Key maternal distress measures}

Anxiety, our main measure of maternal distress, was measured using the Penn State Worry Questionnaire (PSWQ). ${ }^{63}$ This 16-item self-report instrument targets symptoms of worry (eg, 'my worries overwhelm me') and has been successfully used with this population in our previous work ${ }^{64}$ and others'. ${ }^{65}$ We included measures of complementary constructs that capture other aspects of maternal distress that had been used in previous studies. These included scales assessing pregnancy-specific 
Table 1 Summary of UPSIDE biospecimen collections

\begin{tabular}{|c|c|c|c|c|c|c|c|c|c|c|}
\hline & \multicolumn{3}{|c|}{ Prenatal (trimesters) } & \multirow[b]{2}{*}{ Birth } & \multicolumn{6}{|c|}{ Infant/child postnatal (months) } \\
\hline & 1 & 2 & 3 & & 1 & 6 & 12 & 24 & 36 & 48 \\
\hline \multicolumn{11}{|l|}{ Blood } \\
\hline Plasma & M & M & M & UC & & $\mathrm{C}$ & $\mathrm{C}$ & & & C \\
\hline Whole blood & & & M & & & & & & & \\
\hline Urine & $\mathrm{M}$ & M & M & & $\mathrm{C}$ & $\mathrm{C}$ & $\mathrm{C}$ & & & C \\
\hline \multicolumn{11}{|l|}{ Saliva } \\
\hline Diurnal (5x/day) & M & M & M & & & & & & & \\
\hline Stress response & & & & & & $\mathrm{C}$ & $\mathrm{C}$ & $\mathrm{C}$ & & C \\
\hline Oral microbiome & M & M & M & & & $\mathrm{C}$ & $\mathrm{C}$ & $\mathrm{C}$ & & C \\
\hline Rectal swab & & & & $\mathrm{C}$ & $\mathrm{C}$ & $\mathrm{C}$ & $\mathrm{C}$ & C & & \\
\hline Stool & & & & & C & C & & & & \\
\hline Breast milk & & & & & M & $M$ & & & & \\
\hline Nails & & & & & & & $\mathrm{C}$ & $\mathrm{C}$ & & \\
\hline
\end{tabular}

C, child; M, maternal; P, placenta; UC, umbilical cord (artery and vein); UPSIDE, Understanding Pregnancy Signals and Infant Development.

anxiety, ${ }^{3}$ depression, ${ }^{66}$ domestic abuse and violence, ${ }^{67} 68$ global stress, ${ }^{69}$ stressful life events, ${ }^{22} 70$ adverse childhood experiences (ACEs), ${ }^{71}$ discrimination, ${ }^{72}$ aggression $^{73}$ and neighbourhood stress. ${ }^{74}$ To complement these measures of distress, we additionally assessed social support ${ }^{75}$ and relationship satisfaction. ${ }^{76}$

\section{Covariates assessed by maternal surveys}

To complement the extensive maternal distress measures described earlier, at prenatal visits mothers completed additional measures on related to psychosocial stress and/or child neurodevelopment. These will be used as covariates in models to address primary aims (where applicable) or in secondary data analyses. Specifically, validated measures on physical activity, ${ }^{77}$ sleep $^{78}$ and $\operatorname{diet}^{79-81}$ were collected at multiple timepoints prenatally and postnatally. To assess maternal cognition, an important predictor of child neurodevelopment, participants completed a mental rotation task ${ }^{82}$ and an abbreviated verbal comprehension subtest of the Wechsler Adult Intelligence Scale IV. ${ }^{83}$

\section{Prenatal maternal biospecimen collection and analysis}

UPSIDE collected extensive maternal biospecimens as described in table 1 . In addition to the specific analyses described, for all sample types, additional aliquots were banked for future research.

\section{Blood}

In each trimester, a $40 \mathrm{~mL}$ blood sample was collected and processed to provide aliquots of serum, plasma, cells and whole blood (third trimester only) for a variety of analyses. Ongoing analysis of these samples includes (1) sex steroid hormones (estrone, estradiol, estriol, testosterone and free testosterone) using liquid chromatography with tandem mass spectrometry (LC-MS/MS) ${ }^{84}$ (2) placental corticotropin releasing hormone using radioimmunoassay; $^{85}$ (3) immune and related markers (eg, high sensitivity cytokines, $\mathrm{C}$ reactive protein, TGF-beta, angiogenic markers and Mullerian inhibiting factor). Maternal blood was collected by labour and delivery nursing staff on admission for delivery for additional assessment of immune markers.

\section{Saliva}

Participants were trained to collect diurnal saliva for cortisol measurement using the standard passive drool procedures developed by the MacArthur Research Network on Socioeconomic Status and Health. ${ }^{86}$ Samples (approximately $1 \mathrm{~mL}$ ) were collected at home at five predetermined points across the day (at wake-up, $45 \mathrm{~min}$ after wake-up, 2.5 hours after wake-up, 8 hours after wake-up, 12 hours after wake-up) on a single day in each trimester (for a total of 5 samples per trimester or 15 samples across the pregnancy). An additional passive drool saliva sample was collected by mothers at face-toface visits and will be used to assess the oral microbiome.

\section{Urine}

At each prenatal visit, a urine sample was collected, after which the specific gravity (dilution) and temperature of 
Table 2 Summary of upside child assessments

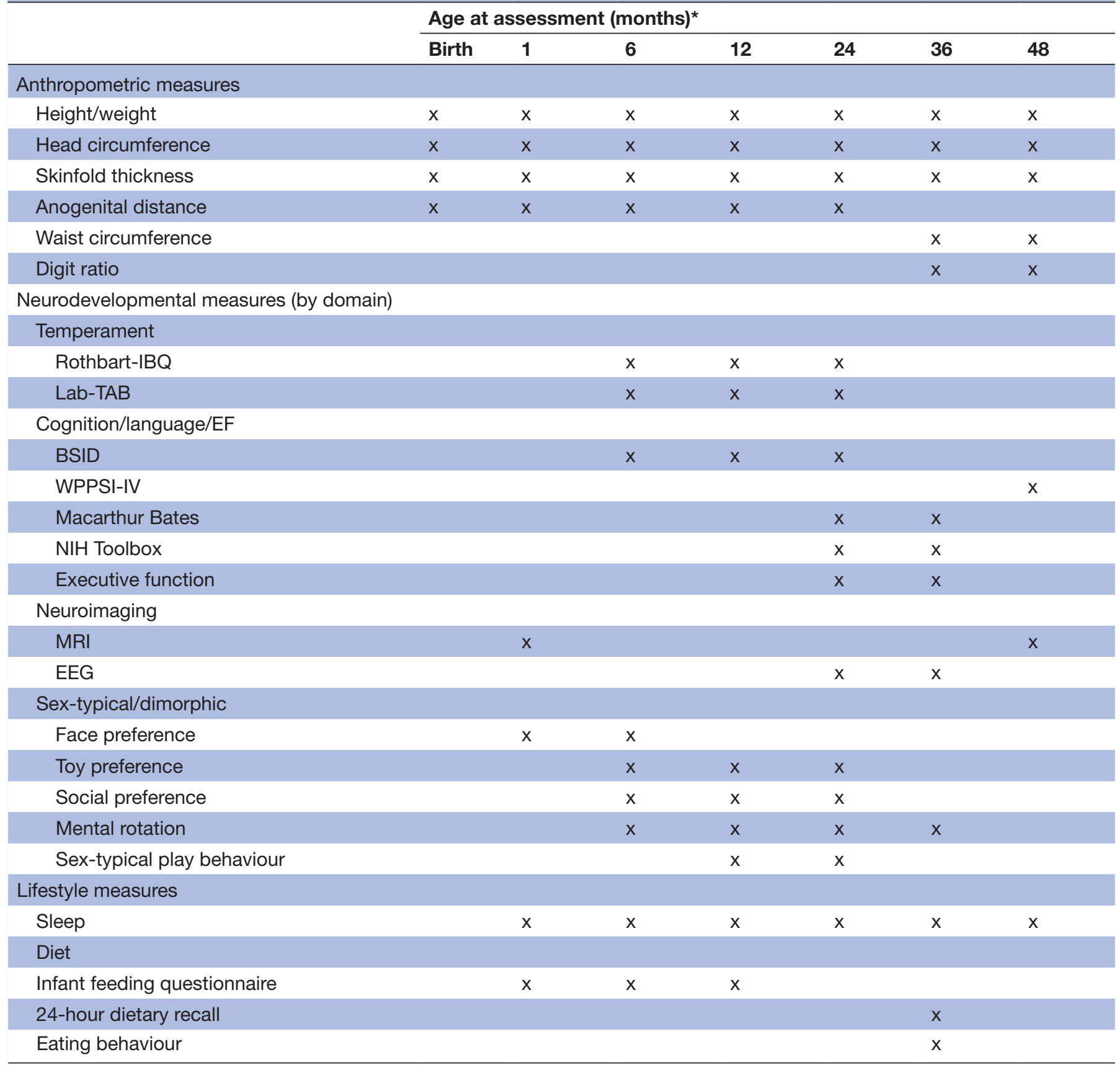

${ }^{*} 6,12,24,36^{*} 6,12,24,36$-month visits are ongoing and 48-month visits will start in early 2021.

BSID, Bayley Scales of Infant Development; EEG, electroencephalogram; EF, executive function; IBQ, Infant Behavior Questionnaire; LabTAB, Laboratory Temperament Assessment Battery; NIH, National Institutes of Health; WPPSI, Wechsler Preschool and Primary Scale of Intelligence.

the sample were measured using a handheld refractometer (National Instrument Company, USA). Five millilitre were frozen for future use.

\section{Buccal swab}

In the third trimester, a buccal cell sample for DNA analysis was collected by swabbing the inside of the participant's cheek (MAWI iSWAB, 250 series) after which samples were stored according to manufacturer guidelines.

\section{Vaginal swab}

In the third trimester, when a vaginal swab was taken by the provider to test for the presence of Streptococcus B as part of standard obstetric care, an additional swab was collected for future analysis of the vaginal microbiome.

\section{Birth biospecimen collection and analysis}

Samples were collected at the time of delivery (usually within 1 hour) and banked at $-80^{\circ} \mathrm{C}$. Analyses including 
hormone and immune assays, environmental chemical assessments and genetics are ongoing.

\section{Cord bloods}

Cord bloods were collected in two venues: (1) mixed cord bloods (up to $25 \mathrm{~mL}$ ) from the delivery room by delivery staff and (2) fetal arterial and venous bloods (up to $30 \mathrm{~mL}$ each) drawn from the placental vasculature by trained coordinators immediately following delivery. The bloods collected from the cord, umbilical vein and umbilical artery were placed into additive free tubes, K2-EDTA tubes and sodium heparin tubes, depending on the volume collected. Peripheral blood mononuclear cells extracted using Ficoll-Paque and red blood cells reserved from processing cord bloods were stored in liquid nitrogen.

\section{Placental tissue collection}

Fresh core villous tissue was collected by a trained coordinator using a flap technique to leave the maternal decidua surface intact. For RNA analysis, two $50 \mathrm{mg}$ tissue sections were washed in phosphate buffered saline, placed in cryovials and flash frozen in liquid nitrogen. About $30 \mathrm{~g}$ of additional placental tissue was extracted using the same technique and frozen unwashed in liquid nitrogen for other types of analyses.

\section{Placental pathology}

All placentae underwent a detailed pathology examination that included standard gross and histological protocols as well as novel assessment of placental vascularisation patterns on the chorionic plate. Using a standard digital camera with polarising filters, a trained coordinator took a series of two-dimensional photographs of the fresh tissue prior to core villous specimen sampling. From the two-dimensional photographs, fetal vascular data will be extracted, arterial and venous surface vascular networks mapped, and virtual slices created. Chorionic surface vasculature branching will be further analysed using computer extraction techniques, yielding continuous measures including number of branch generations, number of branches off base of cord, number of branch points in network, and mean distance from end of artery to end of nearest vein.

Additional photos were taken after removal of the placental specimens to indicate locations of the collections. Weight was collected after removal of the cord and membranes using a standard scale, and cord length was measured (to the nearest $0.1 \mathrm{~cm}$ ) using a tape measure. Cord twists were counted to measure the twist index. Biopsies of the cord were taken at the insertion site and $10 \mathrm{~cm}$ from the insertion site, then placed in cassettes. A section of membrane was cut into a square and rolled, then placed in a cassette. Placentae were reviewed by a pathologist to assess for histology, anomalies and infections. All tissues were placed into formalin for fixation for at least 72 hours. After fixation, the placentae were sectioned and images were obtained of each section. Biopsies of tissue from four quadrants, plus any additional abnormal tissues that were noted, were collected into cassettes for further analysis. The remaining tissues were retained for future assessments.

\section{Three-dimensional placental imaging}

Three-dimensional digital scans of all placentae were collected to assess placental morphology. The custombuilt scanner consisted of two webcams mounted on a bar providing binocular view, and a turntable on which the placenta was placed. The scanner took 8 images of the top and bottom of the placenta and the software assembled these resulting 16 images into a three-dimensional shape. Morphometric measures obtained from threedimensional images include estimated volume, surface area, thickness, shape and symmetric difference.

\section{Prenatal and birth record abstraction}

Clinical data were abstracted from the URMC eRecord system. Prenatal record abstraction included medical, surgical, gynaecological, and reproductive history, prenatal visit records, ultrasound measurements and clinical lab values. Delivery chart abstraction included admission date and time, gestational age on admission, labour onset and duration, rupture of membranes, highest intrapartum temperature, group B Streptococcus status, maternal white blood cells, delivery date and time, fetal position and mode of delivery, complications, medications and maternal morbidity. In addition, relevant data from newborn nursery records were abstracted including birth weight and length, head circumference, Apgar scores, admission unit for baby, first recorded temperature, first recorded blood glucose, Kaiser sepsis risk score, cord arterial $\mathrm{pH}$, neonatal resuscitation and neonatal complications.

\section{Child study activities (ongoing)}

Child visits occur at birth as well as 1, 6, 12, 24, 36 and 48 months of age. Consistent with the study emphasis on longitudinal measures over time, many assessments are repeated at multiple time points, as age appropriate. At present, all birth and 1-month visits have been completed, whereas 6, 12, 24 and 36-month visits are ongoing, and 48-month visits will start in early 2021. Here, we provide an overview of the child data collected across all of these timepoints by domain of interest. Activities conducted are displayed by visit timepoint in table 2 . Our primary child outcome measures represent two domains: neurodevelopment and growth. Secondarily, we collect data on additional constructs as required for ECHO-wide projects and/or to use as covariates in analyses.

\section{Neurodevelopment}

Given the focus on neurodevelopment as a primary outcome, UPSIDE study children participate in an extensive battery of neurodevelopmental assessments that span constructs and method (eg, cognition and language, temperament and behaviour, sex-dependent neurodevelopment, eating behaviours and neuroimaging) (table 2). Importantly, although practice effects sometimes occur 
in older children when measures are closely spaced (ie, several weeks apart), this is unlikely to occur in children this young with visits spaced many months or years apart.

\section{Cognition and language}

The Bayley Scales of Infant Development-III (BSID-III), a widely used tool for assessing mental and motor development in infants and toddlers, is administered at 6, 12 and 24 months. ${ }^{87}$ Of primary interest are the cognitive scaled-score and the language scaled-score, including both receptive and expressive communication subtests which assess memory, sensorimotor development, preverbal behaviours and communication and vocabulary development. At 24 months, complementary data on early vocabulary are obtained through the MacArthurBates Communicative Development Inventory: words and gestures which asks parents to mark on a checklist which phrases, words and sound effects their child understands, says or signs. ${ }^{88}$ Executive function is assessed at 24 and 36 months using age-appropriate standardised tasks that evaluate the child's working memory ('Spin the Pots'), impulse control ('Snack Delay') and inhibitory control ('Reverse Categorisation') ${ }^{89-91}$ At 36 and 48 months we administer additional tasks from the NIH ToolBox Early Childhood Cognition Battery including: Flanker Inhibitory Control and Attention Test (executive function and attention), Dimensional Change Card Sort Test (cognitive flexibility), Picture Sequence Memory (episodic memory) and Picture Vocabulary Test (language development). ${ }^{92-95}$ Finally, at age 4 years, the Wechsler Preschool and Primary Scale of Intelligence (WPPSI-IV) is administered to facilitate calculation of verbal, performance and full scale intelligence quotient. ${ }^{96}$

\section{Temperament and behaviour}

The Laboratory Temperament Assessment Battery (Lab$\mathrm{TAB}$ ) is an observational tool for examining multiple dimensions of infant temperament. ${ }^{97}$ We administer Lab-TAB fear tasks involving the presentation of an unpredictable mechanical toy (6, 12 and 24 months) and a remote-controlled spider (12 and 24 months). In the anger/frustration task ( 6 and 12 months), the infant is allowed to engage with a novel toy and is subsequently interrupted by gentle arm restraint. At 6, 12 and 24 months, mothers complete the Infant Behavior Questionnaire-Revised, a 191-item questionnaire on infant temperament that assesses 14 different dimensions (approach, vocal reactivity, high intensity pleasure, smile and laughter, activity level, perceptual sensitivity, sadness, distress to limitations, fear, falling reactivity, low intensity pleasure, cuddliness, duration of orienting, soothability, social fear, attentional shifting) ${ }^{98}$ At 12 months we also administer the strange situation procedure, widely used to assess parent-infant attachment relationships. ${ }^{99} 100$

\section{Sex-dependent neurodevelopment}

To address study aims regarding sex steroid pathways and the potentially sex-dependent impacts of maternal distress, we administer a series of specialised tasks that, in previous research, have demonstrated sex differences even in early infancy. At 1 and 6 months, infants engage in a task assessing preferences for faces. ${ }^{101}$ At 6,12 and 24 months, children complete a series of computer-based tasks assessing preferences for sex-stereotypical toys (eg, doll vs toy truck) and social stimuli. ${ }^{102}{ }^{103}$ A computerised mental rotation task developed for use in infants is administered at 6, 12, 24 and 36 months. ${ }^{104}$ Finally at 12 and 24 months, the child engages in an independent play task designed to assess preferences for stereotypically women, men and gender neutral toys. ${ }^{105}$

\section{Eating behaviours}

Of relevance to both neurodevelopment and physical development, eating behaviours are assessed using multiple questionnaires and observational tasks at the child's 36-month visit. The Children's Eating Behavior Questionnaire, Preschool Adapted Liking Survey and Comprehensive Feeding Practices Questionnaire are completed by the parent to indicate the child's eating behaviours and parental influences, such as food responsiveness, emotional overeating, food preference, food restriction and family food environment. ${ }^{106-108}$ Food reinforcement is an observational task used to examine the reinforcing value of food in children, which indicates motivation to eat. ${ }^{109} \mathrm{~A}$ food ranking task was developed to evaluate the child's ability to indicate his/her food preference by ranking pictures of food items. To complement the eating behaviour tasks and provide information on the child's usual dietary intake, at the 36-month visit, the parent completes 24-hour dietary recalls for the child (similar to the one completed by mothers during pregnancy).

\section{Neuroimaging}

At 1 month of age, MRI was collected on a Siemens Prisma with a 32 channel head coil using a standard protocol that assesses anatomical scans, diffusion tensor imaging, and resting state functional connectivity. MRI was conducted while the infant was in natural sleep. A follow-up MRI will be performed at age 4 , which will also include functional assessments. When the child is 24 and 36 months, an EEG assessment is conducted. In the EEG, select stimuli are presented and the brain's measured response, known as event-related potentials (ERP), is recorded. Our stimulus is an auditory ERP, called mismatch negativity (MMN). In the MMN assessment, repetitive sounds are interrupted by an occasional odd sound, that differs in frequency and duration.

\section{Physical development}

At each visit, child anthropometric measurements are collected by trained research coordinators. In general, measurements are collected in duplicate at each time point, with a third measurement obtained when the first two differ by more than a prespecified amount (which varies by specific measure and age). Weight, length and 
head circumference are measured at every postnatal visit using standard protocols. ${ }^{110}$ Weight (to the nearest $0.01 \mathrm{~kg}$ ) is measured using a Seca Infant Scale (Model \#334). Length (to the nearest $0.1 \mathrm{~cm}$ ) is measured using a Seca Infantometer (Model\#416), tape measure or wallmounted stadiometer (depending on age). Head circumference is measured by placing a tape measure just above eyebrows and wrapping it around the widest part of the head. Skinfold thicknesses (suprailiac, subscapular and tricep) are obtained to the nearest $0.1 \mathrm{~mm}$ using calibrated Holtain callipers. ${ }^{110} 111$ From birth to 24 months, anogenital distance, a marker of prenatal androgen exposure, is measured to the nearest $0.1 \mathrm{~mm}$ using dial Vernier callipers. ${ }^{112}$ A second purported measure of prenatal androgen exposure, second to fourth digit ratio (2D:4D) of the child's right hand is measured to the nearest $0.1 \mathrm{~mm}$ at 36 and 48 months also using dial Vernier calipers. ${ }^{113}$ Finally, at 36 and 48 months, waist circumference is measured to the nearest $0.1 \mathrm{~cm}$ by wrapping a tape measure around the body at the level of the umbilicus. $^{110}$

\section{Child biospecimen collection}

Postnatal biospecimen collection occurs at each child visit (table 1). Analysis of immune and HPA axis markers is ongoing, whereas additional analysis of banked biospecimens is pending.

\section{Rectal swab}

At birth as well as 1, 6, 12 and 24 months, a sterile swab applicator is dipped into sterile phosphate buffered saline, inserted into the child's anal orifice up to the floxed portion of the swab, and stored in a conical tube for future microbiome analyses. ${ }^{114}$

\section{Buccal swab}

At birth, 12, 24 and 48 months, a buccal specimen is collected for genetic analysis at least $60 \mathrm{~min}$ after the last recorded feeding. Both cheeks are swabbed using a Mawi iSWAB collection kit (250 series) and the vial is stored according to manufacturer guidelines.

\section{Saliva}

At 6, 12, 24 and 48 months, saliva is collected to measure cortisol using Salimetrics SalivaBio swabs. To assess cortisol response to a stressor (blood draw at 6 months, strange situation task at 12 months, physical examination at 24 months) a series of swabs are collected: at the start of the visit ( 6 and 24 months only), prestressor, 15 min poststressor and 30 min poststressor. At 24 and 48 months, an additional saliva swab is collected for assessment of the oral microbiome.

\section{Stool}

At 1 and 6 months, a stool sample is collected at study visits using standard protocols (or by parents using an at-home collection kit if sample collection at the visit is not possible).

\section{Urine}

Urine is collected at the 1, 6 and 12-month visits using an Earth's Best chlorine free diaper equipped with either a urine collection bag and/or sterile cotton balls.

\section{Blood}

At 6,12 and 48 months, approximately $10 \mathrm{~mL}$ of blood is collected by a paediatric nurse $(4 \mathrm{~mL}$ in a K2-EDTA tube and $3 \mathrm{~mL}$ in each of 2 sodium heparin tubes at 6 and 12 months, $8 \mathrm{~mL}$ into a sodium heparin tube, $2 \mathrm{~mL}$ into a K2-EDTA tube and $3 \mathrm{~mL}$ into a tube without additives at 48 months).

\section{Nails}

At 12, 24 and 36 months, fingernails and toenails are collected at study visits (or by parents using an at-home collection kit).

\section{Breastmilk}

Mothers who are breastfeeding at 1 and 6 months provide a breastmilk sample (up to $45 \mathrm{~mL}$ ). Mothers collect the sample during the visit (when possible) using a new, sterile Harmony Medela manual breast pump. When that is not possible, mothers bring in a breastmilk sample that was collected at home.

\section{Statistical analysis and power calculations}

Complementary analyses are planned to address the aims of the UPSIDE cohort. In general, we will employ longitudinal models to test key hypotheses, examining the mediated routes by which associations may occur. We anticipate fitting regression models to determine associations between maternal exposures and child outcomes and will use structural equation modelling to examine potential mediators. Covariates will differ by the particular analyses of interest and will be included based on a priori knowledge and/or a least absolute shrinkage and selection operator (LASSO) approach depending on the particular analysis.

Power calculations were informed by results from our prior cohort studies and indicated that the study would be appropriately powered with a sample size of approximately 290 mother-child dyads. These original power calculations were designed to address hypotheses related to sex steroid pathways, as those were the first set of funded aims at the time of cohort establishment. For example, with an anticipated correlation of 0.19 , we would have $90 \%$ power to detect a significant slope in the regression of maternal anxiety (PSWQ scores) on concentrations of estriol, an oestrogen of primarily placental origin. For our hypothesis on PSWQ scores in relation to anogenital distance (AGD; a marker of prenatal sex steroid activity), with an estimated correlation of 0.25 between maternal PSWQ scores and girls' AGD, we would have $81 \%$ power to detect a slope $\neq 0 \%$ and $86 \%$ power to detect a sexanxiety interaction (with boys' slope $=-0.13$ ). Retention of 226 children at age 12 months would provide $89 \%$ power to detect an association between maternal PSWQ scores and play behaviour in girls, with weaker or no associations 
expected in boys. These power calculations are provided as illustrative analyses with the recognition that there will be variation in power based on the particular question under consideration. Additionally, for some highly novel analyses (eg, maternal serial inflammatory markers in relation to child MRI data), unfortunately there is a lack of effect size data on which to power the study.

\section{Findings to date}

In total, 312 women were recruited into the study, of whom 14 enrolled for more than one pregnancy, resulting in a total of 326 study pregnancies (table 3; figure 1). Of these, 294 mothers gave birth to an infant in the study. The 32 women who signed informed consent but did not give birth to a study infant included 3 screen failures, 5 pregnancy losses, 8 who became ineligible during pregnancy, 2 who were lost to follow-up and 14 who chose to withdraw. Here, we report on the mothers who gave birth to an infant in the study.

On average, women were $28.9 \pm 4.7$ years old at recruitment and the majority were White $(61.2 \%)$ or Black (25.5\%), with $9.9 \%$ reporting Hispanic ethnicity. The participants were socioeconomically diverse with a $34.2 \%$ having a high school degree or less, while $25.7 \%$ had obtained a post-college degree. At the time of recruitment $74.9 \%$ were employed and $60.3 \%$ were married or living as married. Self-reported alcohol use and smoking during early pregnancy were both relatively uncommon (3.4\% and $7.8 \%$, respectively).

The cohort was mildly psychosocially risk enriched and overall symptoms were stable across trimesters with interclass correlation coefficient's for the various psychosocial scales ranging from 0.68 to 0.80 (table 4 ). At baseline, over $50 \%$ were characterised as moderate or high anxiety (based on PSWQ scores) There was a small increase in average Edinburgh Postnatal Depression Scale (depression) scores across pregnancy, however, the proportion of women scoring $\geq 13$ (the most stringent clinical cut-off indicating possible depression) was stable across pregnancy $(9.5 \%-10.6 \%$ across trimesters). Women typically worried less about their fetuses after the first trimester, with slight increases in worry about delivery over time. In the third trimester, $67.9 \%$ of women reported at least one ACE, with $16.7 \%$ reporting four or more. Similarly, the average number of stressful life events during pregnancy was relatively low $(2.46 \pm 2.80)$, however there was great inter-individual variation such that some women reported up to 17 events. By design, this was a low-medical risk cohort at recruitment therefore relatively few participants had major pregnancy complications including hypertensive disorders of pregnancy $(\mathrm{n}=22,7.5 \%)$ and gestational diabetes $(n=6 ; 2.0 \%)$. The average gestational age at birth was 39.5 weeks and only $14(4.7 \%)$ babies were born preterm.

Success rates for biospecimen collection were consistently high across trimesters (blood: 95\%-99\%; urine 94\%-97\%; saliva 96\%-100\%). In addition, 272 mothers (93\%) provided a buccal swab for DNA analysis and 258 mothers $(75 \%)$ provided a vaginal swab. At birth, the placenta and cord blood were obtained in $96 \%$ and $88 \%$ of women, respectively. The discrepancy between success in cord blood collection and placenta collection results from the more intensive immediate processing required for the former as even short delays can result in draining or clotting, making collection impossible. Finally, 277 infants (94\%) participated in an exam at birth; of these $271(98 \%)$ provided a buccal swab and a rectal swab (for microbial analysis) was obtained on 261 (94\%). Onemonth visits were recently completed with additional postnatal visits at $6,12,24,36$ and 48 months underway.

\section{Strengths and limitations}

There are several notable strengths of the UPSIDE study. The first is our extensive, rigorous biospecimen collection starting in the first trimester and continuing throughout pregnancy. This was made possible by focusing recruitment and prenatal visits primarily at a small set of obstetric clinics located in close proximity to the labs where processing and storage occurs. Similarly, birth biospecimen collection (placenta and cord blood) is a strength and based on our experience, a large 'SWAT' team is needed for around the clock collection and processing of placentae within 3 hours after birth (ideally within 1 hour). The need for a 24/7 dedicated on call team is further illustrated by the fact that the majority of study births occurred outside of business hours (figure 2). Similarly, we implemented multiple mechanisms to identify when study participants were admitted for delivery. The successful strategies discussed above allowed UPSIDE to acquire $96 \%$ of placentae. Our extensive placental assessments and biorepository will provide exceptionally rich data on both morphology and molecular biology, allowing us to address novel questions about the placenta in relation to maternal exposures and child outcomes.

Another strength of the study is our ongoing intensive longitudinal follow-up of mother-child dyads with a focus on repeated measures to assess intra-individual changes over time. In the prenatal period, for example, our extensive phenotyping of mothers occurred at three time points, which will allow us to look at trimester-specific impacts and to potentially differentiate between different domains of psychosocial distress (eg, anxiety, depression, stressful life events). During the postnatal period, we again adopt this model, with seven visits occurring from birth to age 4 . This intensive visit schedule allows us to assess domains of neurodevelopment (as age-appropriate) over time and facilitates serial collection of relevant biospecimens that may yield mechanistic insights. Our use of standard measures of development and cognition (such as the WPPSI and BSID-III), moreover, is complemented by tools developed to examine more specific aspects of development that are plausibly linked to our pathways of interest (eg, social preferences and sex-typical play behaviour in relation to sex steroids).

At the same time, there are several limitations of note. The deliberate recruitment of low-medical risk 
Table 3 Baseline characteristics of mother-child dyads participating in Understanding Pregnancy Signals and Infant Development $\left(\mathrm{n}=294^{*}\right)$

\begin{tabular}{|c|c|c|c|}
\hline & Mean (SD) & Min-Max & n (\%) \\
\hline \multicolumn{4}{|l|}{ Maternal characteristics $\dagger$} \\
\hline \multicolumn{4}{|l|}{ Continuous/ordinal } \\
\hline Age (years) & $28.9(4.7)$ & $18-41$ & \\
\hline Prepregnancy BMI $\left(\mathrm{kg} / \mathrm{m}^{2}\right)$ & $27.2(6.9)$ & $16.98-49.77$ & \\
\hline Poverty to income ratio & $3.8(3.9)$ & $0.04-44.6$ & \\
\hline Household size (persons) & $3.2(1.5)$ & $1-11$ & \\
\hline Sleep (Pittsburgh Sleep Index) & $6.3(3.5)$ & $0-17$ & \\
\hline \multicolumn{4}{|l|}{ Categorical } \\
\hline \multicolumn{4}{|l|}{ Race } \\
\hline White & & & $180(61.2)$ \\
\hline Black & & & $75(25.5)$ \\
\hline Asian & & & $11(3.7)$ \\
\hline Mixed race & & & $8(2.7)$ \\
\hline Other & & & $20(6.8)$ \\
\hline Hispanic & & & $29(9.9)$ \\
\hline \multicolumn{4}{|l|}{ Education } \\
\hline$<$ High school & & & $8(2.9)$ \\
\hline High school & & & $85(31.3)$ \\
\hline Some college & & & $39(14.3)$ \\
\hline College degree & & & $70(25.7)$ \\
\hline Post-college degree & & & $70(25.7)$ \\
\hline Employed & & & $215(74.9)$ \\
\hline Married/living as married & & & $173(60.3)$ \\
\hline Medicaid status & & & $110(42.1)$ \\
\hline Nulliparous & & & $82(31.3)$ \\
\hline Smoking during pregnancy (any) & & & $23(7.8)$ \\
\hline Alcohol use during pregnancy (any) & & & $10(3.4)$ \\
\hline \multicolumn{4}{|l|}{ Paternal characteristics $\dagger$} \\
\hline Age (years) & $30.9(5.6)$ & $18-57$ & \\
\hline \multicolumn{4}{|l|}{ Race } \\
\hline White & & & $170(59.9)$ \\
\hline Black & & & 79 (27.8) \\
\hline Asian & & & $5(1.8)$ \\
\hline Otherł & & & $30(10.6)$ \\
\hline \multicolumn{4}{|l|}{ Infant characteristics } \\
\hline Female & & & $152(51.7)$ \\
\hline Gestational age at birth (weeks) & $39.5(1.6)$ & $27.7-42.7$ & \\
\hline Birth weight $(\mathrm{g})$ & $3352.8(495.0)$ & 2195-4654 & \\
\hline Birth length $(\mathrm{cm})$ & $51.1(3.1)$ & $40-60$ & \\
\hline
\end{tabular}

*n's for individual variables may differ slightly due to missing data.

†At time of enrolment, with the exception of sleep which was assessed in the second trimester.

¥'Other' includes American Indian/Alaska Native and individuals self-reporting as 'other'.

BMI, body mass index. 


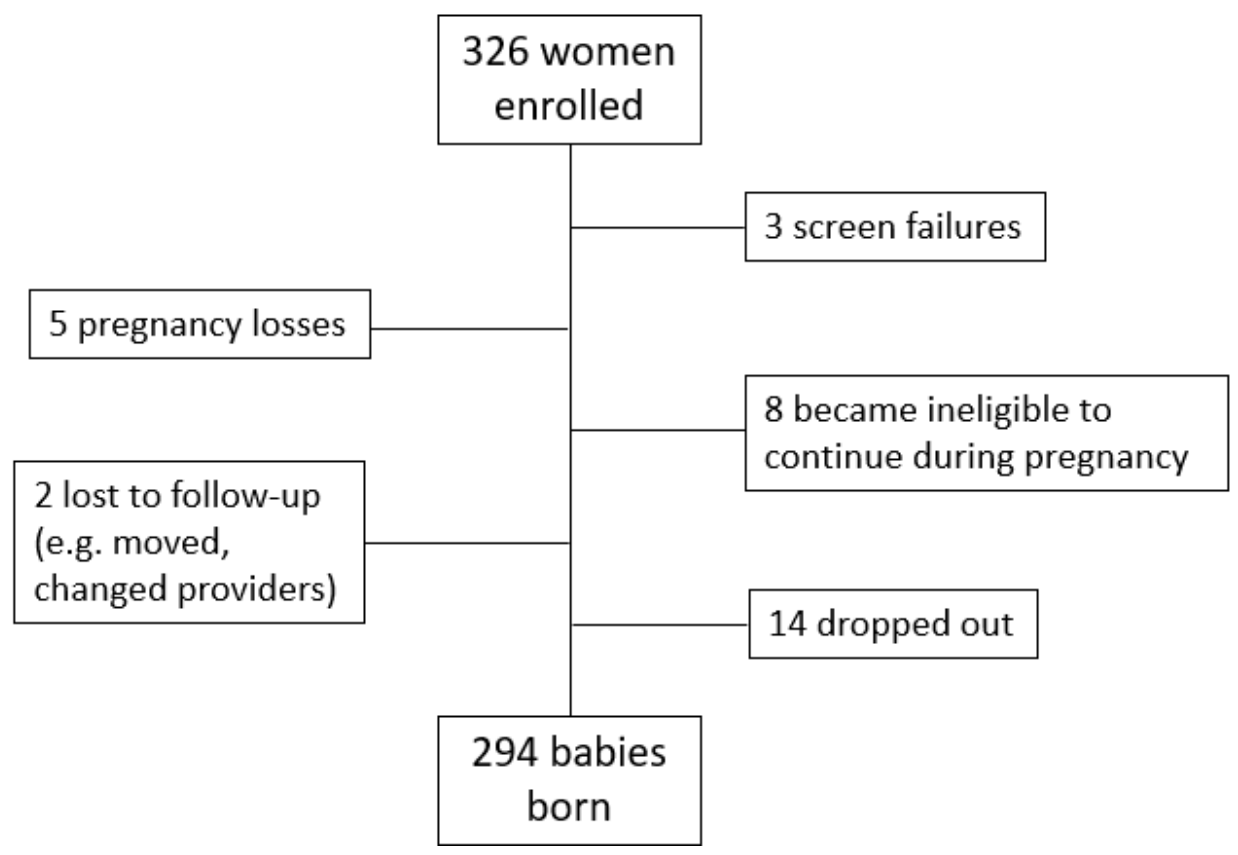

Figure 1 Consort figure on recruitment and retention in the upside study $(n=326)$.

pregnancies means that we are underpowered to test hypotheses regarding pregnancy complications or outcomes. Similarly, our relatively small sample size and overall healthy population precludes examining paediatric clinical outcomes such as birth defects, autism spectrum disorders or developmental delays; however, our ability to look at continuous measures of development will yield insights into neurodevelopmental variation within the typical spectrum. In addition, given evidence that preterm infants develop along a very different trajectory than term infants, preterm infants were not included in postnatal follow-up, so we cannot look at outcomes in this special group. Finally, although the biological and psychosocial contributions of partners is of great interest and relevance to children's development, our prior work in this population suggested that partner attendance at visits was likely to be low, making consent and data collection quite difficult. Thus like many pregnancy cohorts, our data on partners is limited to information provided by the participating women.
Collaboration

Interested investigators may contact the Principal Investigators (EB, TO'C) in writing regarding potential collaborations involving data and/or biospecimens from the UPSIDE study. Potential collaborators will be asked to write a concept proposal for their proposed analysis which will be reviewed by the UPSIDE executive committee. After concept proposal approval, collaborators will submit analysis plans and proof of IRB approval to the Executive Committee prior to receiving data/ samples. Requests for collaborations will be considered on an ongoing basis; however, in general, external collaborations will be started once the primary study aims have been addressed.

\section{Future directions}

As data are cleaned and final outcome data become available, our highest priority is to address the primary study aims for the multiple projects that support this cohort. Beyond our current aims, the rich biospecimen

\begin{tabular}{|c|c|c|c|c|}
\hline & Trimester 1 & Trimester 2 & Trimester 3 & \\
\hline Scale & mean $\pm S D$; (range) & mean $\pm S D$; (range) & mean $\pm S D$; (range) & ICC \\
\hline Depressive Symptoms (EPDS) & $5.56 \pm 4.73(0-21)$ & $5.94 \pm 4.93(0-23)$ & $5.95 \pm 5.13(0-29)$ & 0.73 \\
\hline Anxiety Symptoms (PSWQ) & $44.41 \pm 13.36(16-77)$ & $44.09 \pm 13.72(17-80)$ & $44.31 \pm 13.69(16-80)$ & 0.80 \\
\hline \multicolumn{5}{|l|}{ Pregnancy Specific Anxiety } \\
\hline Worries about the baby & $7.97 \pm 4.3(4-20)$ & $7.24 \pm 3.77(4-20)$ & $7.18 \pm 3.99(4-20)$ & 0.68 \\
\hline Worries about delivery & $6.96 \pm 3.64(3-15)$ & $6.65 \pm 3.46(3-15)$ & $7.19 \pm 3.47(3-15)$ & 0.72 \\
\hline Perceived Stress (PSS) & $19.9 \pm 8.11(2-42)$ & $20.03 \pm 8.1(0-49)$ & $19.83 \pm 8.03(2-39)$ & 0.77 \\
\hline
\end{tabular}

EPDS, Edinburgh Postnatal Depression Scale; ICC, interclass correlation coefficient; PSS, Perceived Stress; PSWQ, Penn State Worry Questionnaire. 


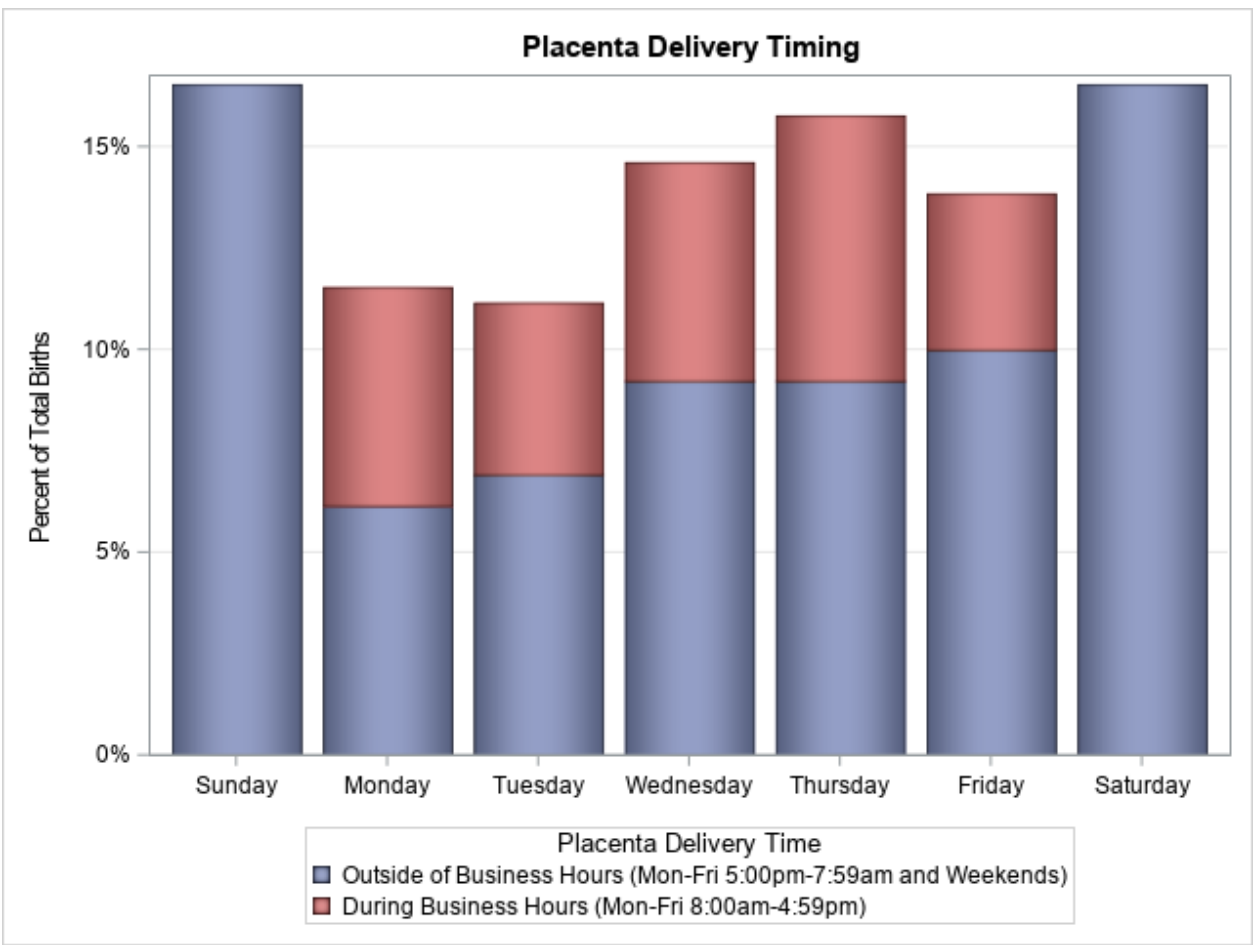

Figure 2 Timing of placental delivery in relation to standard work hours (spontaneous births only).

collection and intensive phenotyping of the UPSIDE cohort lends itself to a wide range of ancillary studies and future directions. At present, ancillary studies to examine environmental chemicals (synthetic chemicals and metals) and air pollution in relation to placental function, perinatal outcomes and infant development are in progress. Also underway is a complementary study of participating mothers looking at trajectories of cardiometabolic health from early pregnancy through 3 years post partum. Additional studies are planned to examine the microbiome (vaginal, oral, gut and breastmilk) in relation to various endpoints including paediatric oral health and neurodevelopment. As part of the ECHO consortium, data and biospecimens from our cohort are harmonised with up to 50000 other participating mother-child dyads from cohort studies around the USA with the goal of providing novel insights into factors that shape multiple facets of children's health (including prenatal, perinatal and postnatal outcomes, upper and lower airway health, obesity, neurodevelopment and positive health).

\section{Author affiliations}

${ }^{1}$ Psychiatry, University of Rochester, Rochester, New York, USA

${ }^{2}$ Obstetrics and Gynecology, University of Rochester Medical Center, Rochester, New York, USA

${ }^{3}$ Neuroscience, University of Rochester Medical Center, Rochester, New York, USA ${ }^{4}$ Wynne Center for Family Research, University of Rochester Medical Center, Rochester, New York, USA

${ }^{5}$ Psychology, University of Rochester, Rochester, New York, USA

${ }^{6}$ School of Nursing, University of Rochester Medical Center, Rochester, New York, USA

${ }^{7}$ Public Health Sciences, University of Rochester Medical Center, Rochester, New York, USA
${ }^{8}$ Placental Modulation Laboratory, Institute for Basic Research in Developmental Disabilities, Staten Island, New York, USA

${ }^{9}$ Placental Analytics LLC, Larchmont, New York, USA

${ }^{10}$ Biostatistics and Epidemiology, Rutgers School of Public Health, Piscataway, New Jersey, USA

${ }^{11}$ Environmental and Occupational Health Sciences Institute, Rutgers University, Piscataway, New Jersey, USA

\section{Twitter Emily Barrett @emilysbarrettphd}

Acknowledgements We acknowledge the contributions of Jessica Alawi-Dugovic, Sanjukta Bandyopadhyay, Jennifer Carnahan, Srihari Chari, Jennifer Dutra, Simone Greenberg, Katie Helbig, Maia Homsi, Zoe Irving, Dan Kaplan, Nate Laniewski, Anne Mientkiewicz, Jessica Mitchell, Aurora Newman, Lisa Panisch, Ryan Prawel, Jenelle Putzig, Amanda Rubano, Andrew Shay, Meghan Sheahan, David Skrill, Jiatong Sui, Sophia Turbide, Meghana Vulapalli, Bailey Walters, Gloria Wink and Zidian Xie. We also acknowledge the mothers and babies who participate in UPSIDE.

Collaborators UPSIDE study collaborators include: Jennifer Adibi, Lauren Aleksunes, Mary Caserta, Susan Groth, Philip Katzman, Eva Pressman, Xing Qiu, Zorimar Rivera-Nunez, Kristin Scheible, Ruchit Shah, Loralei Thornburg, and Sally Thurston.

Contributors EB and TO'C designed the study with significant conceptual contributions to specific portions from RKM, CMS and YM. JB, AVS, AAC, AC, NK, MB, JS, HM, LK, AM and AK led data acquisition. EB and TO'C led manuscript development with intellectual content for subsections provided by all coauthors. All authors provided final approval for the version to be published and agree to be accountable for all aspects of the work.

Funding Funding for the UPSIDE-ECHO study is provided by Eunice Kennedy Shriver National Institute of Child Health and Human Development (R01HD083369), NIH Office of the Director grants (UG30D023349; UH30D023349), National Institute of Environmental Health Sciences (R01ES029275, R01ES029275-02S1, R01ES029336), National Institute of Nursing Research (R01NR01760203, K23NR019014) and the Mae Stone Goode Foundation (no grant number). Additional support is provided by the National Institute of Environmental Health Sciences (P30ES005022, P30ES001247), National Center for Advancing Translational Sciences (TL1TR000096) and the Wynne CenterCentre for Family Research (no grant number).

Competing interests None declared. 
Patient and public involvement Patients and/or the public were not involved in the design, or conduct, or reporting, or dissemination plans of this research.

Patient consent for publication Not required.

Ethics approval This study was approved by the University of Rochester School of Medicine and Dentistry Institutional Review Board (\#58456) and the Rutgers University Institutional Review Board (PR020160001514).

Provenance and peer review Not commissioned; externally peer reviewed.

Data availability statement No data are available. Once complete cohort data have been collected and cleaned, it will be made available to collaborators pending approved concept proposal, analysis plan and documentation of IRB approval.

Open access This is an open access article distributed in accordance with the Creative Commons Attribution Non Commercial (CC BY-NC 4.0) license, which permits others to distribute, remix, adapt, build upon this work non-commercially, and license their derivative works on different terms, provided the original work is properly cited, appropriate credit is given, any changes made indicated, and the use is non-commercial. See: http://creativecommons.org/licenses/by-nc/4.0/.

\section{ORCID iD}

Emily Barrett http://orcid.org/0000-0001-9463-524X

\section{REFERENCES}

1 O'Connor TG, Heron J, Golding J, et al. Maternal antenatal anxiety and children's behavioural/emotional problems at 4 years. Report from the Avon longitudinal study of parents and children. $\mathrm{Br} J$ Psychiatry 2002;180:502-8.

2 Buss C, Davis EP, Hobel CJ, et al. Maternal pregnancy-specific anxiety is associated with child executive function at 6-9 years age. Stress 2011;14:665-76.

3 Huizink AC, Robles de Medina PG, Mulder EJH, et al. Stress during pregnancy is associated with developmental outcome in infancy. $J$ Child Psychol Psychiatry 2003;44:810-8.

4 O'Connor TG, Heron J, Glover V. Antenatal anxiety predicts child behavioral/emotional problems independently of postnatal depression. J Am Acad Child Adolesc Psychiatry 2002;41:1470-7.

5 Talge NM, Neal C, Glover V, et al. Antenatal maternal stress and long-term effects on child neurodevelopment: how and why? J Child Psychol Psychiatry 2007;48:245-61.

6 Welberg LA, Seckl JR. Prenatal stress, glucocorticoids and the programming of the brain. J Neuroendocrinol 2001;13:113-28.

7 Buffa G, Dahan S, Sinclair I, et al. Prenatal stress and child development: a scoping review of research in low- and middleincome countries. PLoS One 2018;13:e0207235.

8 Ramchandani PG, Richter LM, Norris SA, et al. Maternal prenatal stress and later child behavioral problems in an urban South African setting. J Am Acad Child Adolesc Psychiatry 2010;49:239-47.

9 MacGinty RP, Kariuki SM, Barnett W, et al. Associations of antenatal maternal psychological distress with infant birth and development outcomes: results from a South African birth cohort. Compr Psychiatry 2020;96:152128.

10 Herba CM, Glover V, Ramchandani PG, et al. Maternal depression and mental health in early childhood: an examination of underlying mechanisms in low-income and middle-income countries. Lancet Psychiatry 2016;3:983-92.

11 Hentges RF, Graham SA, Plamondon A, et al. A developmental cascade from prenatal stress to child internalizing and Externalizing problems. J Pediatr Psychol 2019;44:1057-67.

12 O'Donnell KJ, Glover V, Lahti J, et al. Maternal prenatal anxiety and child COMT genotype predict working memory and symptoms of ADHD. PLoS One 2017;12:e0177506.

13 Barker DJ. Fetal origins of coronary heart disease. Br Heart $J$ 1993;69:195-6.

14 Barker DJ. The fetal origins of coronary heart disease. Eur Heart $J$ 1997;18:883-4.

15 Hales CN, Barker DJ. Type 2 (non-insulin-dependent) diabetes mellitus: the thrifty phenotype hypothesis. Diabetologia 1992;35:595-601.

16 Jones A, Osmond C, Godfrey KM, et al. Evidence for developmental programming of cerebral laterality in humans. PLoS One 2011;6:e17071.

17 Godfrey KM, Gluckman PD, Hanson MA. Developmental origins of metabolic disease: life course and intergenerational perspectives. Trends Endocrinol Metab 2010;21:199-205.

18 Hanson M, Gluckman P. Developmental origins of noncommunicable disease: population and public health implications. Am J Clin Nutr 2011;94:1754S-8.
19 Gluckman P, Hanson M. The fetal matrix: evolution, development, and disease. Cambridge, UK: Cambridge University Press, 2005.

20 Hales CN, Barker DJ. The thrifty phenotype hypothesis. Br Med Bull 2001;60:5-20.

21 Hoffman DJ, Powell TL, Barrett ES, et al. Developmental origins of metabolic disease. Physiol Rev 2020. doi:10.1152/ physrev.00002.2020. [Epub ahead of print: 03 Dec 2020].

22 Bergman K, Sarkar P, O'Connor TG, et al. Maternal stress during pregnancy predicts cognitive ability and fearfulness in infancy. J Am Acad Child Adolesc Psychiatry 2007;46:1454-63.

23 Buitelaar JK, Huizink AC, Mulder EJ, et al. Prenatal stress and cognitive development and temperament in infants. Neurobiol Aging 2003;24 Suppl 1:S53-60.

24 DiPietro JA, Hilton SC, Hawkins M, et al. Maternal stress and affect influence fetal neurobehavioral development. Dev Psychol 2002;38:659-68.

25 Lobel M, Dunkel-Schetter C, Scrimshaw SC. Prenatal maternal stress and prematurity: a prospective study of socioeconomically disadvantaged women. Health Psychol 1992;11:32-40.

26 O'Connor TG, Heron J, Golding J, et al. Maternal antenatal anxiety and behavioural/emotional problems in children: a test of a programming hypothesis. J Child Psychol Psychiatry 2003;44:1025-36.

27 Stapleton LRT, Schetter CD, Westling E, et al. Perceived partner support in pregnancy predicts lower maternal and infant distress. $J$ Fam Psychol 2012;26:453-63.

28 Beijers R, Buitelaar JK, de Weerth C. Mechanisms underlying the effects of prenatal psychosocial stress on child outcomes: beyond the HPA axis. Eur Child Adolesc Psychiatry 2014;23:943-56.

29 Gao Y, Huang Y, Li X. Interaction between prenatal maternal stress and autonomic arousal in predicting conduct problems and psychopathic traits in children. J Psychopathol Behav Assess 2017;39:1-14

30 Hantsoo L, Kornfield S, Anguera MC, et al. Inflammation: A Proposed Intermediary Between Maternal Stress and Offspring Neuropsychiatric Risk. Biol Psychiatry 2019;85:97-106.

31 Hechler C, Borewicz K, Beijers R, et al. Association between psychosocial stress and fecal microbiota in pregnant women. $\mathrm{Sci}$ Rep 2019;9:4463.

32 Thayer ZM, Wilson MA, Kim AW, et al. Impact of prenatal stress on offspring glucocorticoid levels: a phylogenetic meta-analysis across 14 vertebrate species. Sci Rep 2018;8:4942.

33 O'Donnell KJ, Bugge Jensen A, Freeman L, et al. Maternal prenatal anxiety and downregulation of placental 11 $\beta$-HSD2. Psychoneuroendocrinology 2012;37:818-26.

34 Seth S, Lewis AJ, Saffery R, et al. Maternal prenatal mental health and placental $11 \beta-H S D 2$ gene expression: initial findings from the Mercy pregnancy and emotional wellbeing study. Int $\mathrm{J} \mathrm{Mol} \mathrm{Sci}$ 2015;16:27482-96.

35 Kivlighan KT, DiPietro JA, Costigan KA, et al. Diurnal rhythm of cortisol during late pregnancy: associations with maternal psychological well-being and fetal growth Psychoneuroendocrinology 2008;33:1225-35.

36 Niknazar S, Nahavandi A, Najafi R, et al. Parents' adulthood stress induces behavioral and hormonal alterations in male rat offspring. Behav Brain Res 2013;252:136-43.

37 O'Keane V, Lightman S, Marsh M, et al. Increased pituitary-adrenal activation and shortened gestation in a sample of depressed pregnant women: a pilot study. J Affect Disord 2011;130:300-5.

38 Obel C, Hedegaard M, Henriksen TB, et al. Stress and salivary cortisol during pregnancy. Psychoneuroendocrinology 2005;30:647-56.

39 Suglia SF, Staudenmayer J, Cohen S, et al. Cumulative stress and cortisol disruption among black and Hispanic pregnant women in an urban cohort. Psychol Trauma 2010;2:326-34.

40 Malkova NV, Yu CZ, Hsiao EY, et al. Maternal immune activation yields offspring displaying mouse versions of the three core symptoms of autism. Brain Behav Immun 2012;26:607-16.

41 Monje ML, Toda H, Palmer TD. Inflammatory blockade restores adult hippocampal neurogenesis. Science 2003;302:1760-5.

42 Short SJ, Lubach GR, Karasin Al, et al. Maternal influenza infection during pregnancy impacts postnatal brain development in the rhesus monkey. Biol Psychiatry 2010;67:965-73.

43 Allswede DM, Yolken RH, Buka SL, et al. Cytokine concentrations throughout pregnancy and risk for psychosis in adult offspring: a longitudinal case-control study. Lancet Psychiatry 2020;7:254-61.

44 Brown AS, Begg MD, Gravenstein S, et al. Serologic evidence of prenatal influenza in the etiology of schizophrenia. Arch Gen Psychiatry 2004;61:774-80. 
45 Zerbo O, losif A-M, Walker C, et al. Is maternal influenza or fever during pregnancy associated with autism or developmental delays? results from the charge (childhood autism risks from genetics and environment) study. J Autism Dev Disord 2013:43:25-33.

46 Day DB, Collett BR, Barrett ES, et al. Prenatal sex hormones and behavioral outcomes in children. Psychoneuroendocrinology 2020;113:104547.

47 Brüggemann M, Licht O, Fetter Éva, et al. Knotting nets: molecular junctions of interconnecting endocrine axes identified by application of the adverse outcome pathway concept. Environ Toxicol Chem 2018;37:318-28.

48 Izvolskaia MS, Tillet Y, Sharova VS, et al. Disruptions in the hypothalamic-pituitary-gonadal axis in rat offspring following prenatal maternal exposure to lipopolysaccharide. Stress 2016;19:198-205.

49 Nguyen T-V, Jones SL, Elgbeili G, et al. Testosterone-cortisol dissociation in children exposed to prenatal maternal stress, and relationship with aggression: project ice storm. Dev Psychopathol 2018;30:981-94.

50 Sarkar P, Bergman K, Fisk NM, et al. Amniotic fluid testosterone: relationship with cortisol and gestational age. Clin Endocrinol 2007;67:743-7.

51 Jansson T, Powell TL. Role of the placenta in fetal programming: underlying mechanisms and potential interventional approaches. Clin Sci 2007:113:1-13.

52 Thornburg KL, Marshall N. The placenta is the center of the chronic disease universe. Am J Obstet Gynecol 2015;213:S14-20.

53 Chambers JC, Fusi L, Malik IS, et al. Association of maternal endothelial dysfunction with preeclampsia. JAMA 2001;285:1607-12.

54 Ray JG, Vermeulen MJ, Schull MJ, et al. Cardiovascular health after maternal placental syndromes (CHAMPS): population-based retrospective cohort study. The Lancet 2005;366:1797-803.

55 Seely EW, Tsigas E, Rich-Edwards JW. Preeclampsia and future cardiovascular disease in women: how good are the data and how can we manage our patients? Semin Perinatol 2015;39:276-83.

$56 \mathrm{Li} \mathrm{Q}$, Kappil MA, Li A, et al. Exploring the associations between microRNA expression profiles and environmental pollutants in human placenta from the National Children's Study (NCS) Epigenetics 2015;10:793-802.

57 Tegethoff M, Greene N, Olsen J, et al. Maternal psychosocial stress during pregnancy and placenta weight: evidence from a national cohort study. PLoS One 2010;5:e14478.

58 Yang C, Song G, Lim W. A mechanism for the effect of endocrine disrupting chemicals on placentation. Chemosphere 2019;231:326-36.

59 Park BY, Misra DP, Moye J, et al. Placental gross shape differences in a high autism risk cohort and the general population. PLoS One 2018;13:e0191276.

60 Chang J-M, Zeng H, Han R, et al. Autism risk classification using placental chorionic surface vascular network features. BMC Med Inform Decis Mak 2017;17:162.

61 Misra DP, Salafia CM, Charles AK, et al. Placental measurements associated with intelligence quotient at age 7 years. J Dev Orig Health Dis 2012;3:190-7.

$62 \mathrm{NIH}$. Environmental influences on child health outcomes (echo) program, 2021. Available: https://www.nih.gov/research-training/ environmental-influences-child-health-outcomes-echo-program [Accessed 31 Jan 2021].

63 Meyer TJ, Miller ML, Metzger RL, et al. Development and validation of the Penn state worry questionnaire. Behav Res Ther 1990;28:487-95.

64 O'Connor TG, Scheible K, Sefair AV, et al. Immune and neuroendocrine correlates of temperament in infancy. Dev Psychopathol 2017;29:1589-600.

65 Goodman JH, Guarino A, Chenausky K, et al. CALM pregnancy: results of a pilot study of mindfulness-based cognitive therapy for perinatal anxiety. Arch Womens Ment Health 2014;17:373-87.

66 Cox JL, Holden JM, Sagovsky R. Detection of postnatal depression. development of the 10-item Edinburgh postnatal depression scale. Br J Psychiatry 1987;150:782-6.

67 McFarlane J, Parker B, Soeken K, et al. Assessing for abuse during pregnancy. severity and frequency of injuries and associated entry into prenatal care. JAMA 1992;267:3176-8.

68 Robertson Blackmore E, Mittal M, Cai X, et al. Lifetime exposure to intimate partner violence and proinflammatory cytokine levels across the perinatal period. J Womens Health 2016;25:1004-13.

69 Cohen S, Kamarck T, Mermelstein R. A global measure of perceived stress. J Health Soc Behav 1983;24:385-96.

70 Barnett BE, Hanna B, Parker G. Life event scales for obstetric groups. J Psychosom Res 1983;27:313-20.
71 Felitti VJ, Anda RF, Nordenberg D, et al. Relationship of childhood abuse and household dysfunction to many of the leading causes of death in adults. The adverse childhood experiences (ACE) study. Am J Prev Med 1998;14:245-58.

72 Krieger N, Smith K, Naishadham D, et al. Experiences of discrimination: validity and reliability of a self-report measure for population health research on racism and health. Soc Sci Med 2005;61:1576-96.

73 Buss AH, Perry M. The aggression questionnaire. J Pers Soc Psychol 1992;63:452-9.

74 Ewart CK, Suchday S. Discovering how urban poverty and violence affect health: development and validation of a neighborhood stress index. Health Psychol 2002;21:254-62.

75 Cohen S, Mermelstein R, Kamarck T. Measuring the functional components of social support. In: Sarason I, Sarason B, eds. Social support: theory, research, and application. The Hague, The Netherlands: Martinus Nijhoff, 1985: 73-94.

76 Funk JL, Rogge RD. Testing the ruler with item response theory: increasing precision of measurement for relationship satisfaction with the couples satisfaction index. J Fam Psychol 2007;21:572-83.

77 Chasan-Taber L, Schmidt MD, Roberts DE, et al. Development and validation of a pregnancy physical activity questionnaire. Med Sci Sports Exerc 2004;36:1750-60.

78 Buysse DJ, Reynolds CF, Monk TH, et al. The Pittsburgh sleep quality index: a new instrument for psychiatric practice and research. Psychiatry Res 1989;28:193-213.

79 Johnson RK, Driscoll P, Goran MI. Comparison of multiple-pass 24hour recall estimates of energy intake with total energy expenditure determined by the doubly labeled water method in young children. J Am Diet Assoc 1996;96:1140-4.

80 Feskanich D, Sielaff BH, Chong K, et al. Computerized collection and analysis of dietary intake information. Comput Methods Programs Biomed 1989;30:47-57.

81 Tooze JA, Midthune D, Dodd KW, et al. A new statistical method for estimating the usual intake of episodically consumed foods with application to their distribution. J Am Diet Assoc 2006;106:1575-87.

82 Peters M, Laeng B, Latham K, et al. A redrawn Vandenberg and Kuse mental rotations test: different versions and factors that affect performance. Brain Cogn 1995;28:39-58.

83 Drozdick L, Wahlstrom D, Zhu J. The Wechsler Adult Intelligence Scale-Fourth Edition and the Wechsler Memory ScaleFourth Edition. In: Flanagan D, Harrison P, eds. Contemporary intellectual assessment: theories, tests, and issues: Guilford press, 2012: 197-223.

84 Barrett ES, Mbowe O, Thurston SW, et al. Predictors of steroid hormone concentrations in early pregnancy: results from a multicenter cohort. Matern Child Health J 2019;23:397-407.

85 Smith R, Smith JI, Shen X, et al. Patterns of plasma corticotropinreleasing hormone, progesterone, estradiol, and estriol change and the onset of human labor. $J$ Clin Endocrinol Metab 2009;94:2066-74.

86 Stewart J, Seeman T. Salivary cortisol measurement MacArthur research network on Ses and health, 2000. Available: https:// macses.ucsf.edu/research/allostatic/salivarycort.php [Accessed 27 Aug 2020].

87 Bayley N. Bayley scales of infant and toddler development: administration manual. San Antonio, TX: Harcourt Assessment, 2006.

88 Fenson L, Marchman V, Thal D. MacArthur-Bates Communicative Development Inventories: User's Guide and Technical Manual. 2nd edition, 2007.

89 Hughes C, Ensor R. Executive function and theory of mind in 2 year olds: a family affair? Dev Neuropsychol 2005;28:645-68.

90 Kochanska G, Murray KT, Harlan ET. Effortful control in early childhood: continuity and change, antecedents, and implications for social development. Dev Psychol 2000;36:220-32.

91 . Executive function scale for preschoolers test manual. Minneapolis, MN Institute of Child Development, University of Minnesota.

92 Weintraub S, Bauer PJ, Zelazo PD, et al. I. NIH Toolbox cognition battery (CB): introduction and pediatric data. Monogr Soc Res Child Dev 2013;78:1-15.

93 Zelazo PD, Anderson JE, Richler J, et al. II. NIH Toolbox cognition battery (CB): measuring executive function and attention. Monogr Soc Res Child Dev 2013;78:16-33.

94 Bauer PJ, Dikmen SS, Heaton RK, et al. III. NIH Toolbox cognition battery (CB): measuring episodic memory. Monogr Soc Res Child Dev 2013;78:34-48.

95 Gershon RC, Slotkin J, Manly JJ, et al. IV. NIH Toolbox cognition battery $(\mathrm{CB})$ : measuring language (vocabulary comprehension 
and reading decoding). Monogr Soc Res Child Dev 2013;78:49-69.

96 Weschler D. Wechsler preschool and primary scale of intelligence. 4th ed. Bloomington, IL: Pearson, 2012.

97 Goldsmith H, Rothbart M. The laboratory temperament assessment battery, locomotor version. 3.1 ed. Madison, WI University of Wisconsin- Madison; 1999

98 Gartstein MA, Rothbart MK. Studying infant temperament via the revised infant behavior questionnaire. Infant Behavior and Development 2003;26:64-86.

99 Ainsworth MD, Bell SM. Attachment, exploration, and separation: illustrated by the behavior of one-year-olds in a strange situation. Child Dev 1970;41:49-67.

100 Ainsworth MD, Blehar M, Waters E. Patterns of attachment: a psychological study of the strange situation. Hillsdale, $\mathrm{NJ}$ : Lawrence Erlbaum, 1978

101 Connellan J, Baron-Cohen S, Wheelwright S, et al. Sex differences in human neonatal social perception. Infant Behavior and Development 2000;23:113-8.

102 Alexander GM, Wilcox T, Woods R. Sex differences in infants' visual interest in toys. Arch Sex Behav 2009;38:427-33.

103 Lutchmaya S, Baron-Cohen S. Human sex differences in social and non-social looking preferences, at 12 months of age. Infant Behavior and Development 2002;25:319-25.

104 Moore DS, Johnson SP. Mental rotation of dynamic, threedimensional stimuli by 3-Month-Old infants. Infancy 2011;16:435-45.

105 LamminmÃaki A, Hines M, Kuiri-HÃanninen T, et al. Testosterone measured in infancy predicts subsequent sex-typed behavior in boys and in girls. Horm Behav 2012;61:611-6.
106 Wardle J, Guthrie CA, Sanderson S, et al. Development of the Children's Eating Behaviour Questionnaire. J Child Psychol \& Psychiat 2001;42:963-70.

107 Peracchio HL, Henebery KE, Sharafi M, et al. Otitis media exposure associates with dietary preference and adiposity: a communitybased observational study of at-risk preschoolers. Physiol Behav 2012;106:264-71.

108 Musher-Eizenman D, Holub S. Comprehensive feeding practices questionnaire: validation of a new measure of parental feeding practices. J Pediatr Psychol 2007;32:960-72.

109 Temple JL, Legierski CM, Giacomelli AM, et al. Overweight children find food more reinforcing and consume more energy than do nonoverweight children. Am J Clin Nutr 2008;87:1121-7.

110 Westat. National health and nutrition examination survey III body measurements (anthropometry). Rockville, MD; 1988.

111 Bush NR, Allison AL, Miller AL, et al. Socioeconomic disparities in childhood obesity risk: association with an oxytocin receptor polymorphism. JAMA Pediatr 2017;171:61-7.

112 Sathyanarayana S, Grady R, Redmon JB, et al. Anogenital distance and penile width measurements in the infant development and the environment study (TIDES): methods and predictors. J Pediatr Urol 2015;11:76.e1-76.e6.

113 Manning JT, Scutt D, Wilson J, et al. The ratio of 2 nd to 4 th digit length: a predictor of sperm numbers and concentrations of testosterone, luteinizing hormone and oestrogen. Hum Reprod 1998:13:3000-4.

114 Grier A, Qiu X, Bandyopadhyay S, et al. Impact of prematurity and nutrition on the developing gut microbiome and preterm infant growth. Microbiome 2017;5:158. 